IZA DP No. 9414

Social Ties in Academia: A Friend is a Treasure

Tommaso Colussi

October 2015 


\title{
Social Ties in Academia: A Friend is a Treasure
}

\section{Tommaso Colussi}

IZA

\section{Discussion Paper No. 9414 October 2015}

\author{
IZA \\ P.O. Box 7240 \\ 53072 Bonn \\ Germany \\ Phone: +49-228-3894-0 \\ Fax: +49-228-3894-180 \\ E-mail: iza@iza.org
}

\begin{abstract}
Any opinions expressed here are those of the author(s) and not those of IZA. Research published in this series may include views on policy, but the institute itself takes no institutional policy positions. The IZA research network is committed to the IZA Guiding Principles of Research Integrity.

The Institute for the Study of Labor (IZA) in Bonn is a local and virtual international research center and a place of communication between science, politics and business. IZA is an independent nonprofit organization supported by Deutsche Post Foundation. The center is associated with the University of Bonn and offers a stimulating research environment through its international network, workshops and conferences, data service, project support, research visits and doctoral program. IZA engages in (i) original and internationally competitive research in all fields of labor economics, (ii) development of policy concepts, and (iii) dissemination of research results and concepts to the interested public.
\end{abstract}

IZA Discussion Papers often represent preliminary work and are circulated to encourage discussion. Citation of such a paper should account for its provisional character. A revised version may be available directly from the author. 
IZA Discussion Paper No. 9414

October 2015

\section{ABSTRACT}

\section{Social Ties in Academia: A Friend is a Treasure ${ }^{*}$}

This paper employs a unique dataset on articles, authors and editors of the top general interest journals in economics to investigate the role of social connections in the publication process. Ties between editors and authors are identified based on their academic histories. Results show that an editor's former PhD students and faculty colleagues experience an increase in their publication outcomes when this editor is in charge of a journal. The analysis of articles' citations suggests that connections ultimately improve the quality of published papers.

JEL Classification: $\quad A 1,123, \mathrm{~J} 24$

Keywords: academia, networks, human capital

Corresponding author:

Tommaso Colussi

Institute for the Study of Labor (IZA)

Schaumburg-Lippe-Str. 5-9

53113 Bonn

Germany

E-mail: colussi@iza.org

\footnotetext{
* I am very grateful to Marco Manacorda for invaluable advice and guidance. For helpful comments I thank Ghazala Azmat, Gaetano Basso, Emmanuel Guerre, Daniel Hamermesh, Michael Neumann, Michele Pellizzari, Lucia Rizzica, Olmo Silva, and seminar participants at $20^{\text {th }}$ SOLE Meeting, XI Jornadas de Economia Laboral, IZA-Bonn, Queen Mary University of London, the XIII Brucchi Luchino, and the $26^{\text {th }}$ EALE Conference. I am particularly indebted to Alessandro Vecchiato for helping me collecting the data.
} 


\section{Introduction}

The importance of social connections in shaping individual behaviour and economic outcomes has motivated a number of studies in a variety of environments. ${ }^{1}$ In the labour market, much of the literature has analysed how social networks affect their members' employment prospects, such as job search outcomes, wages and promotions (Ioannides and Datcher Loury 2004); only a few studies have instead focused on the efficiency of connections and whether they harm or improve outcomes of selection processes (Bandiera, Barankay and Rasul 2009). The present paper precisely addresses this last issue by exploring the role played by social ties in a particularly stark setting, the publication process in economics. In particular, it empirically investigates the extent to which connections between authors and editors influence articles' selection in economics journals and their quality.

The world of economists who publish in high-impact journals is generally perceived to be small and composed of interconnected scholars. ${ }^{2}$ In 1995 about $71 \%$ of the editors of the 30 most cited journals came from an institution located in the United States and thirteen U.S. universities accommodated about $39 \%$ of all editors. Similarly, $65.7 \%$ of journal articles' authors were located in a U.S. institution and again thirteen universities accounted for $21.8 \%$ of the authors (Hodgson and Rothman, 1999). ${ }^{3}$ The degree of institutional and geographical concentration of authors and editors of top journals in economics seems to be largely skewed to the United States (Ellison, 2002; Kim, Morse and Zingales, 2006).

\footnotetext{
${ }^{1}$ Among different contexts analysed by the empirical literature on network effects there are welfare program participation (Bertrand, Lutmer and Mullanaithan 2000), criminal behaviour (Bayer, Hjalmarsson and Pozen 2009), education (Sacerdote 2001), and sports Guryan, Kroft and Notowidigdo 2009).

${ }^{2}$ Goyal, van der Leij and Moraga-Gonzalez (2006) show that almost half of this population is composed of authors, whose average distance, measured by degrees of academic separation, is relatively short. The distance between two scholars is equal to one if they have co-authored at least one paper; it becomes equal to two if the two scholars have never worked together but they share a co-author, and so on.

${ }^{3}$ These thirteen U.S. universities are Harvard, Chicago University, University of Pennsylvania, Stanford, Northwestern, University of Wisconsin, University of California-Berkeley, University of Michigan, Massachusetts Institute of Technology, Princeton, Yale, New York University, and University of Maryland.
} 
Among different potential explanations for these figures, one is given by sorting of scholars: most talented researchers tend to locate in the same top universities, eventually increasing the gap in academic productivity between elite and non-elite institutions (Kim, Morse and Zingales 2009). A second explanation has to do with peer effects among researchers (Waldinger 2012; Borjas and Doran 2012); the agglomeration of highly productive scholars in a particular university may generate positive spillovers on the scientific production of its members (Azoulay, Graff Zivin and Wang 2010; Waldinger 2010). ${ }^{4}$ Finally, editorial favouritism, i.e. editors' practice of favouring professionally linked scholars in the publication process, might represent a third plausible reason (Laband and Piette 1994; Brogaard, Engelberg and Parsons 2014). ${ }^{5}$

This paper contributes to this last strand of the literature by providing new and clean empirical evidence on the effect of connections in the publication process, further exploring what determinants of network formation are the most relevant in academia. To this end, I employ a unique dataset providing detailed information on academic histories of all scholars that published at least one article, or served as editor, in the top four general interest journals in economics from January 2000 to December 2006; these journals are the American Economic Review, the Journal of Political Economy, Econometrica and the Quarterly Journal of Economics. ${ }^{6}$ The dataset provides yearly information on authors' and editors' academic careers since the time they graduated up to the last year of the

\footnotetext{
${ }^{4}$ Waldinger (2010) uses the expulsion of Jewish scientists in German universities during the Nazi era as an exogenous variation in the quality of universities. He shows that graduate students experienced a decrease in the probability of publication and of getting tenure if enrolled in in institutions experiencing a large quality drop. Azoulay, Graff Zivin and Wang (2010) focus instead on the effect of superstar scientists on the productivity of their co-authors, showing a long lasting decline in their publication rates when the superstar they are linked to dies unexpectedly.

${ }^{5}$ Laband and Piette (1994) find that editorial favoritism serves as a screening device to identify highquality papers for publication. Similarly, Brogaard, Engelberg and Parsons (2014) provide further evidence of the beneficial effect of connections on publication outcomes: the article production of academic institutions raises by roughly $100 \%$ when one of their scholars is appointed as editor of a journal; they further show that "inside" articles have a higher number of citations than "outside" ones.

${ }^{6}$ The selection of journals was based on the 1998 Journal Citation Reports (JCR) ranking provided by Kalaitzidakis, Mamuneas, and Stengos (2003). I exclude from the sample top European journals, such as the Review of Economic Studies and the Journal of the European Economic Association, as this study focuses on North-American networks.
} 
observation period, i.e. 2006. These data allow me to identify whether social ties between each author and each editor actually exist along various dimensions. I focus on four different types of connections: I define an author and an editor to be connected if they have ever worked in the same institution at the same time (Same Faculty); if they received their PhD from the same university in the same years (Same PhD); if the editor was one of the PhD advisors of the author (PhD Advisor); and if the author has ever co-authored at least one paper with the editor (Co-authors). The dataset contains information on 1,620 journal articles written by 2,015 scholars; articles' characteristics include the number of citations, the number of pages, the position within the journal issue and the topic according to the $J E L$ classification.

Measuring the causal effect of connections with an editor on a scholar's publication probability requires to tackle different empirical challenges. First, endogenous group formation represents a threat to identification if scholars who tend to be connected to editors are systematically different from non-connected ones (Soetevent 2006). As editors are usually selected among highly reputed scholars, connected authors are likely to be similarly skilled; a positive correlation between an author's probability of having his paper published and the existence of a link with the editor may be simply driven by unobserved characteristics, such as ability. Second, scholars in the same network may share the same characteristics, such as the field of research, they are thus likely to be exposed to similar shocks in publication trends; this case of correlated effects may induce a positive correlation between a scholar's editorship and the publication probabilities of his connections (Moffitt 2001).

In order to identify the effect of connections on the publication probability, I use a difference-in-differences strategy that exploits variation in the composition of editors within a journal over time. I thus look at differences in the publication outcomes of authors connected to a scholar when this scholar is in charge as an editor and when he is not. Regression results show that the existence of a social tie with an editor positively 
affects scholars' publication outcomes: when a scholar is in charge of a journal, the number of papers published by his connections increases by about two papers in three years. In particular, editors tend to publish papers of scholars working in the same institution and of former graduate students. Faculty colleagues of an editor are also more likely to publish lead and longer articles during that editor's appointment. Being a past co-author of an editor or his classmate during the $\mathrm{PhD}$ does not have an impact on any of the publication outcomes analysed. Falsification exercises confirm that these results are not driven by unobserved characteristics of connected scholars or by publication trends determining the appointment of an editor in a particular field and his connections' improved publication outcomes.

In general there are two competing arguments to explain why a preferential treatment of editors towards connected scholars should arise. On the one hand, professional links may increase the quality of a paper through technological complementarities. The quality of a paper depends on the author's and the editor's input. Pre-existing ties between scholars might reduce the cost of communication and increase cooperation, improving the quality of a paper. ${ }^{7}$ On the other hand, editors may favour connected authors because of taste or nepotism (Bagues and Zinovyeva 2014; Durante, Labartino and Perotti 2011). If this is the case, the publication standards applied by the editor to connected papers may be lower than for non-connected ones, possibly impoverishing the quality of publications. Although these two stories lead to the same implication on the publication probability of connected authors, they predict an opposite sign on the quality of published papers.

The analysis of articles' subsequent citations can shed some light on the prevailing mechanisms at work. I find that articles authored by former PhD students of an editor increase the number of citations by more than $27 \%$ when this editor is in charge. These results suggest that connections between editors and authors give rise to techno-

\footnotetext{
${ }^{7}$ Over the last twenty years, the number of total submissions to top economics journals has almost doubled, while the number of published articles has decreased (Card and Della Vigna 2013). It has become extremely costly for editors to screen the large amount of submissions received. As editors want to publish the best papers, the publication probability of connected scholars may then increase.
} 
logical complementarities, which improve the quality of connected papers. Unexpectedly, there is no statistically significant effect for other types of connections on the number of citations, possibly implying that the positive effects on quality due to technological complementarities are offset by a dilution in quality due to nepotism.

The remainder of the paper is organised as follows. Section 2 presents a simple model to show how connections influence editors' behaviour. I provide details on the data collection and key summary statistics in Section 3. Section 4 describes the empirical strategy. I present and discuss the empirical results in Section 5. Section 6 concludes.

\section{Conceptual framework}

This section provides a theoretical framework to illustrate how editors' choices in the publishing process are influenced by the existence of a social tie with authors, and how these connections ultimately affect the quality of published articles. Social ties may affect editors' behaviour through two channels: tastes and technology. Cooperation is likely to be higher when authors and editors are professionally linked than when they are not. For instance, an editor can more easily review a colleague's paper if he attended the paper's presentation at an internal seminar; or if he can benefit from comments of other researchers working in the same institution. The cooperation between connected scholars then may increase the quality of a paper through technological complementarities. Social ties may also directly enter editors' preferences: either because of altruism or because of a taste for power (Rotemberg 1994; Pendergast and Topel 1996; Bandiera, Barankay and Rasul 2009). ${ }^{8}$

In order to formalise these mechanisms and explore their effects on publication outcomes, assume that a journal editor receives a connected and a non-connected paper to review for publication. The final quality of every submitted paper is given by $y_{c}=\alpha_{c}+k_{c}$;

\footnotetext{
${ }^{8}$ The model of Bandiera, Barankay and Rasul (2009) shows that social connections between workers and managers in the firm increase the level of managerial effort while they have an ambiguous effect on the firm's overall performance.
} 
where $c$ indicates whether the submitted paper is connected $(c=1)$ or non-connected $(c=0) .{ }^{9} \quad$ The quality of a paper depends on the ability of the author $\alpha_{c}$, which for simplicity I assume being normally distributed with mean $\mu$ and variance equal to one, $\alpha_{c} \sim N(\mu ; 1)$. Social ties do not affect the distribution of authors' ability, i.e. $\mu_{0}=\mu_{1}=\mu$; however they can directly affect the quality of submitted papers through the parameter $k_{c}$, which captures the increase in papers' quality due to technological complementarities between authors and editors. For simplicity, I assume that this parameter is equal to zero $\left(k_{0}=0\right)$ for non-connected scholars, and it is positive $\left(k_{1}=k>0\right)$ when there is a tie between the editor and the author.

Editors have to chose which article to publish in order to maximise their payoff, this is:

$$
\max _{D} y_{0}(1-D)+\left(y_{1}+g\right) D
$$

where $D$ is a binary variable that takes value one if the connected paper is published and $g$ is the editor's private return from publishing the work of a connected author.

From the solution of editors' problem, the probability of publishing a connected paper is:

$$
\operatorname{Pr}[D=1]=\operatorname{Pr}\left[\alpha_{1}-\alpha_{0}+(g+k)>0\right] .
$$

Assuming that $\alpha_{1}$ and $\alpha_{0}$ are independently distributed, the probability that an editor will publish the work of a connected author is always greater than one half, i.e $\operatorname{Pr}[D=$ 1] $>1 / 2$.

The first implication of the model is that editors will publish connected papers as long as technological complementarities and/or private returns from publishing the work of a "friend" exist.

From the above equations, it follows that the expected quality of connected published

\footnotetext{
${ }^{9}$ For simplicity I do not model effort choices of both authors and editors in the publication process.
} 
papers is:

$$
E[y \mid D=1]=E\left[y_{1} \mid \alpha_{1}+g+k-\alpha_{0}>0\right]=k+\mu+\sigma \frac{\phi(z)}{1-\Phi(z)},
$$

where $z=\alpha_{1}-\alpha_{0}+(g+k), \frac{\phi(z)}{1-\Phi(z)}$ is the inverse Mills ratio, and $\sigma$ is the standard deviation of $z . \phi($.$) and \Phi($.$) are the pdf and the cdf of the standard normal distribution,$ where $\Phi(z)$ is the probability of publishing a non-connected paper, i.e. $\operatorname{Pr}[D=0]{ }^{10}$

Following the same reasoning, the expected quality of a published non-connected paper is:

$$
E[y \mid D=0]=E\left[y_{0} \mid \alpha_{0}-\left(\alpha_{1}+g+k\right)>0\right]=\mu+\sigma \frac{\phi(z)}{\Phi(z)} .
$$

By subtracting equation 4 from equation 3, the difference in expected quality between connected and non-connected papers is:

$$
E\left[y_{1} \mid D=1\right]-E\left[y_{0} \mid D=0\right]=k+\sigma \frac{\phi(z)[2 \Phi(z)-1]}{\Phi(z)[1-\Phi(z)]}
$$

The first term in equation 5 is the technological parameter, which is positive by assumption $(k>0)$. However from equation 1 it follows that the second term of the equation 5 is always negative, as $\operatorname{Pr}[D=1]>1 / 2$.

The second implication of this theoretical framework is that the differential quality between connected and non-connected papers has an ambiguous sign: technological complementarities increase the quality of connected publications; however because of tastes editors may decide to publish connected papers of a lower quality with respect to nonconnected ones. Therefore as editors' tastes for connected authors increase, technological complementarities must raise too in order to observe a positive effect of connections on papers' quality. These results constitute the basis of the empirical strategy of this paper.

\footnotetext{
${ }^{10}$ Under the assumption that $\alpha_{1}$ and $\alpha_{0}$ are two independent normally distributed variables, it follows that $z \sim N\left(0 ; \sigma^{2}\right)$ where $\sigma^{2}=2$ and the correlation coefficient between $\alpha_{1}$ and $z$ is equal to one.
} 


\section{Data and measures of connections}

The data used in this work provide detailed information on all articles published in the American Economic Review (AER), the Journal of Political Economy (JPE), Econometrica (ECA) and the Quarterly Journal of Economics (QJE), i.e. the leading American general interest journals in economics, over the period 2000-2006. ${ }^{11}$ I exclude from the sample papers published in the Annual Papers and Proceedings issues of the American Economic Review, as well as special issues, announcements, comments, replies or notes.

Data sources for articles are IDEAS-RePEc and Web of Science. ${ }^{12}$ For each article the data report the number of citations received in each year since publication, authors' first and last name, the date and the issue of publication, the number of pages and the field according to the JEL classification (at one-digit level).

Starting from this information, I collected and skimmed each author's curriculum vitae to construct a longitudinal dataset that allows me to follow any scholar in every year since the time they graduated until the last year of observation, i.e. $2006 ;^{13}$ I have information on authors' gender, country of origin, PhD university and year of award, institution in which they are appointed and their position within the institution in every year since graduation, editorial activities and main research fields classified according to the JEL classification. ${ }^{14}$ There are 2,015 authors attached to the articles analysed.

\footnotetext{
${ }^{11}$ Kalaitzidakis, Mamuneas, and Stengos (2003) provide the ranking of journals in economics based on the number of citations in 1998 of articles published in the period 1994-1998, excluding self-citations and adjusted for impact (influence) and size. According to this index, the AER ranks first, followed by ECA, the JPE, and the QJE.

${ }^{12}$ Research Papers in Economics (RePEc) is a collaborative effort of hundreds of volunteers in 76 countries to enhance the dissemination of research in economics. RePEc provides links to over 1.4 million research pieces from 1,700 journals and 3,700 working paper series (http://repec.org/).

Web of Science (WoS) is a scientific citation indexing service that provides a comprehensive citation search. It gives access to about 30,000 scholarly books, 12,000 journals and 148,000 conference proceedings, representing one of the largest citation databases (http://thomsonreuters.com/web-of-science/).

${ }^{13} \mathrm{About} 96 \%$ of the authors in the sample have their CV publicly available on the web; when this was not provided, I gathered information from alternative sources such as Wikipedia or departmental web pages. Missing authors account for less than $3 \%$ of all authors.

${ }^{14} \mathrm{JEL}$ codes are automatically retrieved from IDEAS-RePEc, which lists each author's main research fields based on publication history. Appendix A provides a detailed description of the JEL classification system.
} 
The same information is provided for the 42 scholars that have served as editor for at least one issue in the four journals considered over the period 2000-2006. Editors' name were retrieved from journals' archives and from $J S T O R \cdot{ }^{15} \mathrm{I}$ further recovered from editors' curricula the names of their co-authors up to 2006.

Table 1 reports summary statistics for the articles in the sample. Overall, there are 1,620 articles published in the top four economics journals over 7 years. The American Economic Review is the journal that published the largest number of articles (603), while the Quarterly Journal of Economics the smallest (282). The latter tends to publish longer papers, with an average number of pages equal to $36.9 .{ }^{16}$

Statistics show that the QJE is the most cited journal, while ECA ranks last $(83.2$ vs. 47.6). Figure 1 further explores data on citations, it plots the cumulative distribution of papers' citations by journal: the QJE is also the journal with the smallest share of low-cited articles, i.e. articles with less than 10 citations, and the highest share of highlycited ones, i.e. articles with more than 200 citations. This can be seen by the fact that the QJE's cumulative distribution line is flatter than the one of other journals. Citations indicate the the number of papers that have cited the article in the first eight years after publication, including working papers and self citations; this information was collected in January 2015, so that each paper has a fixed time window of eight years in which it can be cited.

The number of citations is likely to depend on both the length and the field of the article, possibly explaining differences in citations across journals. For instance, ECA mainly publishes econometric and theoretical papers that, in recent years, have been less cited than applied ones (Card and Della Vigna 2013; Hamermesh 2013). On average there are about 2 authors per article, ECA tends to publish papers written by fewer

\footnotetext{
${ }^{15}$ I did not consider potential hierarchies among the editors; for instance, I listed as "editors" both editors-in chief and co-editors.

${ }^{16}$ This value strictly depends on the formatting used by the journal: as of 2006 the AER was the only journal using the two-column format, explaining the lower length of its articles compared to other journals. The AER eventually switched the one-column format in 2008. This journal also publishes in every issue a set of shorter papers that generally do not exceed the 15-page length.
} 
authors while the average number of authors that publish in the QJE is the highest (2.03), potentially explaining differences in citations between these two journals. Moreover, if I restrict the sample to single authored papers, the average number of citations decreases and the differences in citations across journals become smaller.

\subsection{Definition of social connections}

Table 1 also reports the fraction of papers by authors that were connected with at least one editor at the time of the publication. As mentioned in the introduction, I focus on four different types of social ties. The first one, which I define as Same PhD, indicates whether an editor and an author obtained the PhD from the same university in the same time window (allowing for a maximum 3 year gap between graduation dates). About 10\% of the 1,620 articles published in the period 2000-2006 were written by authors connected according to the Same PhD tie. $^{17}$

A PhD Advisor connection is established when an editor had an academic position in the same university and in the same year in which the author obtained his $\mathrm{PhD}$; moreover the two scholars also share at least one research field. Since I do not have information on the $\mathrm{PhD}$ advisors for all the authors in the dataset, this variable proxies for the link between academic advisors and their students. The fraction of connected papers according to this second measure is about 15\%, with the QJE showing the highest figure, i.e. $21 \%$.

I then investigate the role of connections between colleagues; according to this definition two scholars are socially tied if they have ever worked in the same institution in the same period, before the editor becomes in charge of the journal, i.e. Same Faculty. On average, the QJE has the highest share of connected authors according to this last metric, implying that about one fifth of the articles published in the QJE over the period 2000-2006 were written by scholars affiliated with Harvard. ${ }^{18}$

\footnotetext{
${ }^{17}$ Articles authored by more than one scholar are defined as connected if at least one author is linked to an editor of the journal.

${ }^{18}$ The Quarterly Journal of Economics and the Journal of Political Economy are "house journals", i.e.
} 
Finally I examine social ties based on co-authorships; I define an editor and an author as Co-authors if they have ever co-authored at least one paper, either published in a journal or a working paper, up to the year in which the editor started his appointment. The share of Co-authors connected papers is around $8 \%$, journals publishing more papers of editors' co-authors are ECA and the QJE, whose shares are $8.4 \%$ and $11.7 \%$ respectively. Overall, about $43 \%$ of papers published in the four journals considered are authored by at least one scholar that is connected to at least one editor at the time of the publication.

The degree of concentration of this particular "market" can be analysed by computing the Herfindahl index (HHI) of institutions' shares of articles in the top four general-interest journals over the observation period (Ellison 2002). This is the sum of the square of the market share of the largest 50 universities in terms of academic production observed in the data. The market share for each institution is computed as the number of authors employed by the institution at the time of the publication over the total number of authors that have published in the journal. As shown in the last row of Table 1, the QJE is the journal with the highest concentration index, i.e. about $5 \%$. Relatively high values of the HHI index are also found for the JPE, while the AER and ECA show the lowest values of concentration. ${ }^{19,20}$

Figure 2 plots the distribution of authors who published in any of the four journals considered according to their institution. ECA and the AER seem to be more open than the QJE and JPE, which show a bias towards authors appointed at their host institutions. Roughly $10 \%$ of the authors of papers appearing in the JPE were employed by the University of Chicago at the time of the publication. Similarly, only seven universities contributed to $50 \%$ of the articles published by the QJE in the seven years considered,

they have at least one editor coming from the university in which they are hosted, which are Harvard University and the University of Chicago respectively.

${ }^{19} \mathrm{It}$ is hard to comment on the absolute levels of concentration, especially because this market is not comparable to other standard markets; in general, values of the HHI index greater than 0.15 are considered high, implying that the market is an oligopoly with a medium-high level of concentration.

${ }^{20}$ The Herfindahl index for journal $j$ is defined as $H H I_{j}=\sum_{i} s_{i j}^{2}$, where $s_{i j}$ is the fraction of all articles in journal $j$ written by authors affiliated at the institution $i$. 
with Harvard alone accounting for about 15\%. Figure 3 provides even more striking results, it plots the distribution of authors according to the institution of $\mathrm{PhD}$ award. As in Figure 2, top U.S. universities are overrepresented; for instance, Harvard and MIT alone account for about $50 \%$ of all papers published in the QJE.

Table 2 provides a more detailed picture of the characteristics of the editors and authors at the time of publication. The data do not provide the year of birth, however the date of graduation proxies for the "academic age" : less than one author out of four is an early career, i.e. he/she got the $\mathrm{PhD}$ at most four years before the publication. Experienced and male scholars are the most represented groups in the sample, with a share of full professors is roughly $52 \%$ and a share of male economist close to $90 \%$. Despite the growing proportion of women in Academia over the last thirty years (Donald and Hamermesh 2006; Abrevaya and Hamermesh 2012), female authors are still underrepresented in top economics journals. Among the authors in the sample, about $32 \%$ published at least two articles, with some very prolific economists publishing more than ten articles in seven years.

Finally, it is quite interesting to observe that while about $25 \%$ of the authors received their PhD from MIT or Harvard, for editors the share increases to 44\%. Editors are usually male professors, most of them come from the universities of Chicago and Harvard; the share of scholars who are connected to at least one editor of any journal at any time is very high: about half the authors were working in an institution in which at least one editor also worked in the past; moreover, roughly $40 \%$ of authors were supervised by a scholar who was or became editor in one of the top four economics journals.

The idea of economics being a small world seems to be confirmed by these statistics. Whether connections have a causal impact on the probability of publishing and on the quality of publications is thus an empirical question. 


\section{Identification}

The aim of this paper is to estimate the causal effect of connections between scholars and editors on two outcome variables of the publication process: the probability of getting a paper published and the number of citations a paper receives.

The main empirical challenge is that connected authors may have a higher probability of publication in top economics journals than non-connected ones for reasons other than the existence of a tie with the editor. In order to address this issue, my empirical strategy compares publication outcomes of authors connected to a particular editor when this editor is in charge of a journal and when he is not. For each editor $i$ in charge of journal $j$ at time $t$, I identify papers published by authors connected to editor $i$ in the same journal over the whole observation period 2000-2006. I then estimate whether the number of articles connected to editor $i$ and published by journal $j$ changes depending on $i$ 's editorship, based on the following linear regression model:

$$
y_{i j t}=\beta_{0}+\beta_{1} \text { InCharge }_{i j t}+\lambda_{i}+\zeta_{j t}+u_{i j t},
$$

where $y_{i j t}$ is the number of papers connected to editor $i$ that have been published in journal $j$ at time $t$, InCharge is the treatment variable, which takes value one whenever editor $i$ is in charge of journal $j$ at time $t$, and zero otherwise. The coefficient of interest is $\beta_{1}$, which indicates to what extent an appointed editor affects the publication outcomes of connected scholars in journal $j$. Finally $\lambda_{i}$ and $\zeta_{j t}$ are editor and journal*time fixed effects respectively. ${ }^{21}$ Since every journal has different release dates, the time variable is journal specific; in order to circumvent this problem I aggregate issues by semester. ${ }^{22}$

\footnotetext{
${ }^{21}$ If a scholar is appointed as an editor of two different journals I treat him/her as two independent observations. Given the short time window, i.e. seven years, the data just have one scholar, who was editor of two different journals. Therefore, an editor*journal fixed effect would be exactly the same as the editor fixed effect.

${ }^{22}$ The JPE and ECA publish six issues per year, while the AER (excluding the Annual Papers and Proceeding issue) and the QJE only have four issues per year. ECA release dates are January, March, May, July, September and November; for the JPE these dates are February, April, June, August, October, December; the AER releases its issues in March, June, September and December, while the QJE in
} 
The empirical model 6 relies on the comparison of publication outcomes of connected scholars when editor $j$ is in charge and when he is not (Gagliarducci and Manacorda 2014; Lee and Mas 2012). Any unobserved difference between connected and non-connected authors is washed out when considering only researchers connected to a scholar who eventually becomes in charge of a journal. Moreover, editor fixed effects control for the time-invariant unobserved quality of the network, i.e. the group of authors connected to a particular editor. The $\zeta_{j t}$ control absorbs any unobservables affecting journal $j$ at any time $t$, including shifts toward particular research fields. The final specification is then a difference-in-differences model, where journal-time characteristics and editor fixed effects are fully absorbed. The identification of parameter $\beta_{1}$ comes from changes in the composition of editors within the journal $j$ over time. The average duration of the appointment is 3 years, (or 16 issues). In order to identify the parameter of interest, $\beta_{1}$ there must be at least one new editor appointed in each journal over the observation period.

The implicit identifying assumption is that the time of an editor's appointment is orthogonal to unobservables potentially affecting publication outcomes of connected scholars. Conditioning on authors connected to a scholar who eventually becomes editor and given the short-time window analysed this assumption seems plausible. Section 5.3 provides different robustness checks aimed at testing the validity of this assumption.

The definition of the dependent variable $y_{i j t}$ changes depending on the outcome of the publication process considered and the type of social tie analysed. I focus on three outcomes: the number of published papers, number of pages, and number of lead articles in journal $j$ at time $t$. Each outcome variable will then take four different values depending on the type of social tie considered; for instance, an outcome is the number of paper published in journal $j$ at time $t$ by authors connected to editor $i$ because of the $P h D$ Advisor connection. Finally and in line with the theoretical model, to estimate the causal February, May, August and November. 
effect of connections on papers' quality, I define as a dependent variable the average number of citations that connected papers have received in the first eight years after publication.

Before moving to the empirical findings, it is worth mentioning two additional concerns. First, the definition of social ties may just be too wide, potentially defining two persons as connected even if they have never interacted. Second, the data do not provide information on the editor that actually handed the paper; similarly, because of delays in publication I may assign papers to editors that were not in charge at the time of the submission. If this is the case, the explanatory variable of interest, InCharge is measured with error and the estimated coefficient, $\hat{\beta}_{1}$, thus represents a lower bound estimate of the effect of social ties.

\section{Empirical findings}

\subsection{Effects of connections on publication probability}

Table 3 reports estimates of equation 6 . The single observation is represented by the combination of editor $i$, journal $j$ and semester $t$; since I have aggregated observations by semester, the independent variable InCharge $_{i j t}$ is defined as the fraction of journal issues the editor was in charge of, over the total number of journal issues in semester $t .{ }^{23}$ The total number of observations is equal to 588. All the regressions presented in this section include editor and time*journal fixed effects. Standard errors are clustered at the level of the interaction between journal $j$ and time $t .^{24}$

Results in Panel A of Table 3 show that the number of published articles connected to an editor increases when this editor is in charge. In column (1) authors and editors

\footnotetext{
${ }^{23}$ Since journals have different release dates of their issues, the inclusion of a time fixed effects in equation (4) would not be independent of the journal. In order to control for time trends, I need to aggregate the data by term so that the time variable becomes biannual, being no longer journal-specific.

${ }^{24}$ The number of clusters in this case is thus equal to 56 .
} 
are considered as connected if at least one of the five social ties exists, i.e. Pooled. The coefficient is positive and significant; it implies that when the editor is in charge of a journal the number of connected published articles increases by 0.26 papers per semester. Since the average duration of an editorship is about three years, the increase in the number of connected papers published during an editor's appointment is approximately 1.56.

Columns (2) to (5) explore what type of professional link drives the positive coefficient in column (1): the only statistically significant coefficients are the ones for the Same Faculty and the PhD Advisor ties. The number of articles written by authors who have worked in the same institution as the editor raises by about 0.29 articles per semester when the editor is in charge. In other words, authors increase their publication rate by about 10 percent at the baseline when a connected scholar is appointed as the editor of that journal. A lower but still positive and significant effect is found for the $P h D$ advisor connection, the coefficient implies that following the $\mathrm{PhD}$ advisor's appointment as an editor of a journal, the number of publications of his former PhD students increases by about 0.16 articles per semester. All other types of social ties have smaller and not statistically significant effects on this publication outcome.

The data used in this work also provide information on other articles' characteristics, such as the number of pages and the position within the issue, i.e. whether a paper is the lead article. Coupé, Ginsburgh and Noury (2010) use a natural experiment to show that leading papers in randomly ordered issues attract more citations. It is then worth investigating whether connections also have an effect on these two outcomes of the publication process. Panel B of Table 3 presents results of the effect of social ties on the number of pages of articles written by connected scholars (i.e. number of connected pages). Connected authors experience an increase in the number of pages published by about 12 pages per term when one of their connections becomes editor. The effect again is positive and significant for the Same Faculty and PhD Advisor links; the number of pages per article raises by about eleven pages per term when the author is a colleague 
of the editor; while they increase by slightly more than six pages per semester when the author has been a graduate student of the editor, which is equivalent to a $19 \%$ increase at the baseline. Again, all other types of ties do not provide statistically significant results. ${ }^{25}$

Panel $\mathrm{C}$ further provides results on the probability of having a connected paper published as the lead article of the issue. The coefficients are positive for the link based on the institution of appointment, i.e. Same Faculty, while the Phd Advisor is no longer significant. A university colleague experience an increase in the probability of getting a paper published as a lead article by about $10 \%$ when the editor he is connected to becomes in charge. As predicted by the theoretical model in Section 2, the empirical findings presented in Table 3 confirm that editors tend to publish papers of professionally linked scholars: the publication probability, the length of articles and the position within the issue of connected authors increase when editors they are connected to start their appointment. These estimates also indicate that the positive social effect is particularly relevant for some types of connections: $\mathrm{PhD}$ students and university colleagues. According to the first implication of the theoretical model, positive technological complementarities and/or private returns from publishing a "friend" only exist for these two types of connected authors.

\subsection{Effect of connections on articles' quality}

As highlighted in Section 2, there are two potential explanations for the preferential treatment of editors towards connected scholars. On the one hand, professional links foster cooperation between the editor and the author giving rise to technological complementarities, which ultimately improve the quality of the paper. On the other hand, editorial favouritism may arise because of tastes for connected authors independently of the quality of their work, possibly leading to a dilution in the quality of the publication.

\footnotetext{
${ }^{25}$ The coefficient on the number of pages captures an increase both at the extensive and intensive margin. It is thus driven by an increase in the number of connected papers published and in articles' length.
} 
The net effect of connections on the quality of papers is then ambiguous, the analysis of the ex-post citations a paper receives can shed light on the mechanisms driving the results previously found. Citations are a well established measure for a paper's quality although admittedly not perfect. ${ }^{26}$ The data used in this work refer to the total number of citations a paper receives in the first eight years following its release. The information on citations was collected in January 2015 and it reports the number of quotes a paper received in each year after publication; every paper is then given the same time window in which it could be quoted. ${ }^{27}$

Panel D of Table 3 presents regression results of equation 6 where the dependent variable is the average number of citations of connected papers published in journal $j$ at time $t .^{28}$ The econometric specification is the same used in the previous section and it includes editor and time-journal matches fixed effects. Results show that the only significant coefficient is the one for the PhD Advisor connected papers: when the editor is in charge, connected papers receive on average 6.7 more citations than in semesters in which he is not in charge. This result is consistent with editorial favouritism being driven by complementarities between authors' and editors' inputs. It seems that the cooperation and the communication between an editor and an author who have worked together during graduate studies, improve the quality of connected articles. However potential alternative explanations may still hold. For instance, editors may want to raise the bar for papers authored by former graduate students; similarly, authors may choose to submit only the best papers to journals edited by their former PhD supervisor. Both stories eventually translate into an increase in the expected quality of connected articles,

\footnotetext{
${ }^{26}$ One may argue that the number of citations a paper receives do not perfectly reflect its quality. For instance, innovative or controversial papers may need longer time than usual in order to get accepted by the scientific community and thus be cited. The eight-year interval is a reasonable time window that should account for a belated reception of a paper.

${ }^{27}$ Citations were collected in January 2015 from Web of Science database. They include self-citations and working papers; the inclusion of self-citations should not affect the estimated coefficient as the identification strategy compares articles of the same connected authors, before and after the connected editor becomes appointed.

${ }^{28} \mathrm{I}$ decided to use the average instead of the total number of citations, as the latter increases with the number of connected papers published.
} 
such as the technology parameter $k$ in equation 5 .

Interestingly there is no significant increase in citations for papers authored by past and current colleagues: the estimated coefficient is negative but statistically not significant. Editors' tastes for papers authored by university colleagues may offset the potential increase in quality generated by technological complementarities.

\subsection{Robustness checks}

A potential threat to identification is that an editor's appointment might be correlated with his connections' publication outcomes for reasons other than the existence of social ties. For instance, a journal's preference towards papers in a particular research field may simultaneously affect the appointment of an editor, who is a prominent scholar in that field, and publication outcomes of his connections. To test whether this field effect generates spurious correlation potentially biasing estimated coefficients, I estimate whether an editor accepts more papers of authors in his research field when he is in charge than when he is not. I thus define as connected all authors in the same research fields as the editor's, defined by JEL codes (at one digit level). Results are reported in column (7) of Table 3. Panel A reports the estimated coefficient $\beta_{1}$ from equation 6 , where the outcome variable is the number of Same Field published papers. Estimates are not statistically significant and have an opposite sign with respect to coefficients in columns 1, 2 and 3. Moreover, the estimated effect on citations is not driven by a field effect: column (7) of Panel D shows that the positive effect of connections on papers' citations is not driven by editors' input becoming larger when handling a Same Field article.

The empirical model developed in Section 4 implicitly assumes that when an editor finishes his mandate, the publication probability of his connections reverses to the one in pre-editorial terms. This model is univocally restrictive as the state dependence in the publication process may imply that the effects of a connection with a scholar are persistent, even when the editor is no longer in charge. I order to investigate this issue 
further, I estimate the following equation:

$$
y_{i j t}=\gamma_{0}+\gamma_{1} \text { InCharge } e_{i j t}^{e n t r y}+\gamma_{2} \text { InCharge } e_{i j t}^{e x i t}+\lambda_{i}+\zeta_{j t}+\epsilon_{i j t}
$$

where InCharge $e_{i j t}^{\text {entry }}$ is a dummy that is equal to one at any time following editor $j$ 's appointment. The variable InCharge $e_{i j t}^{\text {exit }}$ is another dummy that is one at any time $t$ after editor $j$ finishes his mandate. By subtracting the exit dummy from the entry dummy, I recover the InCharge variable of equation 6, i.e. InCharge $e_{i j t}^{\text {entry }}-$ InCharge ixit $^{\text {exit }}=$ InCharge $_{i j t}$. The coefficient $\gamma_{1}$ then measures the persistence of the editorship's effect, while $\gamma_{2}$ measures the effect of an editor loosing the editorship on connected authors' publication outcomes. ${ }^{29}$ Finally $\zeta_{j t}$ and $\lambda_{i}$ are journal*time and editor fixed effects respectively.

Interestingly results reported in Panel A of Table 4 show that the effects of a connection on publication outcomes are highly persistent. Moreover, these effects do not vanish when the editor terminates his appointment. For instance, the number of articles written by former PhD students increase by 0.37 per semester; however, former PhD students seem not to experience a decrease in publication outcomes when the editorship ends, as the coefficient of the InCharge $e^{\text {exit }}$ is statistically insignificant. Clearly one may interpret these persistent effects as evidence of connections' state dependence; however, I cannot rule out that they may also reflect a delayed effect caused by the time gap between a paper's submission and its publication, i.e. the review times of articles, which usually spans from one to two years (Ellison 2002). ${ }^{30}$

\footnotetext{
${ }^{29}$ By comparing equation 6 and equation 7 , it follows that $\beta_{1}=\left(\gamma_{1}-\gamma_{2}\right) / 2$.

${ }^{30}$ Given the long review process applied by these journals, it is unlikely that papers in a particular issue were chosen and reviewed by a newly appointed editor. The variable InCharge $e^{\text {entry }}$ also accounts for temporal lags when matching editors and authors. To further control for this potential source of measurement error, I alternatively run regressions in which I include a 1-year lag when matching editors with publications. Consistent with column (3) of Table 4, the PhD advisor tie is robust to the inclusion of the 1-year lag, increasing both estimated coefficient's magnitude and significance; as pointed out in Section 4, this type of measurement error biases estimated coefficients down. Nevertheless, I prefer not to present these estimates as review times of connected papers may be systematically different from those for non-connected ones.
} 
Finally, in Panel B of the Table 4 I run placebo regressions in which editors have been randomly assigned to a journal other than the one edited. If connected scholars increase their publication outcomes in different journals when the editor they are connected to is in charge, I cannot rule out that unobservables simultaneously affecting an editor's appointment and his connections' publication outcomes drive estimates in Table 3. Panel B of Table 4 shows that none of the estimated coefficients is statistically significant. This last set of regressions confirms that unobservables seem not to simultaneously influence an editor's appointment and his connections' publication outcomes. Authors experience an increase in the number of paper published only in journals edited by a connected scholar.

\section{Conclusion}

This work has provided clear empirical evidence on the role played by social ties in selection processes. By employing a unique dataset on all the articles published in the leading American general interest journals in economics over the period 2000-2006, I explore how connections between authors and editors affect the publication process in economics and the quality of published papers.

Publications in high-impact journals largely affect hiring, pay and promotions of economists, making the returns to top-journal articles extremely large. ${ }^{31}$ At the same time, it has become more demanding to publish in these journals: the acceptance rate has decreased from $15 \%$ to $6 \%$ in the last thirty years (Card and Della Vigna, 2013). It is thus worth exploring what factors influence the publication process in economics and ultimately affect researchers' careers.

I find that, when a scholar becomes editor of a journal, his connections improve their publication outcomes. The social effect is particularly relevant for former $\mathrm{PhD}$ students and university colleagues of the editor; for instance, during an editor's appointment, the

\footnotetext{
${ }^{31}$ Swidler and Goldreyer (1998) estimate that the present value of the first top finance journal article is between $\$ 19,493$ and $\$ 33,754$. This value represents the marginal contribution of a published article to a professor's salary and an indirect effect of becoming tenured.
} 
number of published articles written by former graduate students increase by $15 \%$ at the baseline. Similarly working in the same institution as the editor increases the number of published articles by about a paper per year when this editor is in charge. The existence of a social tie with the editor influences other outcome variables of the publication process: for university colleagues, both the length of the article and the probability of having a paper published as lead article significantly increase. Interestingly, past co-authors of the editor do not benefit from the editor's appointment in terms of number of published papers.

I developed a simple theoretical framework to illustrate how social ties affect editorial choices. Because of tastes and technological complementarities between connected scholars, editors always prefer to publish papers authored by researchers they are connected to. However, the sign of the differential quality of connected and non-connected papers is ambiguous.

In order to test for the implications of the model, I analyse the effect of social ties on the number of citations that papers receive. Articles by former graduate students of an editor receive on average 6.7 more citations when this editor is in charge, suggesting that complementarities between editors' and authors' inputs in the publication process are driving editors' behaviour. There is no beneficial effect on citations from publishing papers authored by past and current faculty colleagues. The preferential treatment for these types of connections does not lead to any improvement in the quality of published articles.

\section{References}

Abrevaya, Jason and Daniel S. Hamermesh. 2012. "Charity and Favoritism in the Field: Are Female Economists Nicer (To Each Other)?." The Review of Economics and Statistics, 94(1): 202-207.

Azoulay, Pierre, Joshua S. Graff Zivin and Jialan Wang. 2010. "Superstar Extinction," 
The Quarterly Journal of Economics, 125(2): 549-589.

Bagues, Manuel and Natalia Zinovyeva. 2014. "The Role of Connections in Academic Promotions." American Economic Journals: Applied Economics, forthcoming.

Bandiera, Oriana, Iwan Barankay and Imran Rasul. 2009. "Social Connections and Incentives in the Workplace: Evidence From Personnel Data." Econometrica, 77(4): 10471094.

Bayer, Patrick, Randi Hjalmarsson and David Pozen. 2009. "Building Criminal Capital behind Bars: Peer Effects in Juvenile Corrections." The Quarterly Journal of Economics, 124(1): 105-147.

Bertrand, Marianne, Erzo F. P. Luttmer, and Sendhil Mullainathan. 2000. "Network Effects And Welfare Cultures." The Quarterly Journal of Economics, 115(3): 10191055 .

Borjas, George J. and Kirk B. Doran. 2012. "The Collapse of the Soviet Union and the Productivity of American Mathematicians." The Quarterly Journal of Economics, 127(3): 1143-1203.

Brogaard, Jonathan, Joseph Engelberg and Christopher A. Parsons. 2014. "Network Position and Productivity: Evidence from Journal Editor Rotations." Journal of Financial Economics, 111(1): 251-270.

Card, David and Stefano Della Vigna. 2013. "Nine Facts about Top Journals in Economics." Journal of Economic Literature, 51(1): 144-61.

Combes, Pierre-Philippe, Laurent Linnemer and Michael Visser. 2008. "Publish or peerrich? The role of skills and networks in hiring economics professors." Labour Economics, $15(3): 423-441$.

Coupé, Tom, Victor Ginsburgh and Abdul Noury. 2010. "Are leading papers of better quality? Evidence from a natural experiment." Oxford Economic Papers, Oxford University Press, 62(1): 1-11.

Donald, Stephen G. and Daniel S. Hamermesh. 2006. "What is Discrimination? Gender in the American Economic Association, 1935-2004." American Economic Review, 96(4): 1283-1292. 
Durante, Ruben, Giovanna Labartino and Roberto Perotti, 2011. "Academic Dynasties: Decentralization and Familism in the Italian Academia." NBER Working Papers 17572, National Bureau of Economic Research.

Ellison, Glenn. 2002. "The Slowdown of the Economics Publishing Process." Journal of Political Economy, 110(5): 947-993.

Gagliarducci, Stefano and Marco Manacorda. 2014. "Politics in the Family: Nepotism and the Hiring Decisions of Italian Firms." Mimeo.

Goyal, Sanjeev, Marco van der Leij and Jose Moraga-Gonzalez. 2006. "Economics: An Emerging Small World." Journal of Political Economy,114(2): 403-432.

Guryan, Jonathan, Kory Kroft and Matthew J. Notowidigdo. 2009. "Peer Effects in the Workplace: Evidence from Random Groupings in Professional Golf Tournaments." American Economic Journal: Applied Economics, 1(4): 34-68.

Hamermesh, Daniel S. 2013. "Six Decades of Top Economics Publishing: Who and How?." Journal of Economic Literature, 51(1): 162-72.

Hodgson, Geoffrey M. and Harry Rothman. 1999. "The Editors and Authors of Economics Journals: A Case of Institutional Oligopoly?." Economic Journal,109(453): F165-86.

Kalaitzidakis, Pantelis, Theofanis P. Mamuneas and Thanasis Stengos. 2003. "Rankings of Academic Journals and Institutions in Economics." Journal of the European Economic Association, 1: 1346-1366.

Kim, E. Han, Adair Morse and Luigi Zingales. 2006. "What Has Mattered to Economics Since 1970." Journal of Economic Perspectives, 20(4): 189-202.

Kim, E. Han, Adair Morse and Luigi Zingales. 2009. "Are elite universities losing their competitive edge?." Journal of Financial Economics, 93(3): 353-381.

Ioannides, Yannis M. and Linda Datcher Loury. 2004. "Job Information Networks, Neighbourhood Effects, and Inequality." Journal of Economic Literature, 42:1056-1093.

Laband, David N. and Michael J. Piette. 1994. "Favoritism versus Search for Good Papers: Empirical Evidence Regarding the Behavior of Journal Editors." Journal of Political Economy, 102(1): 194-203. 
Lee, David and Alexandre Mas. 2012. "Long-Run Impacts of Unions on Firms: New Evidence from Financial Markets, 1961-1999." The Quarterly Journal of Economics, $127(1): 333-378$

Moffitt, Robert A. 2001. "Policy Interventions, Low-Level Equilibria, and Social Interactions." In Social Dynamics, ed. Steven N. Durlauf and H. Peyton Young, 45-82. Cambridge, MA: MIT Press.

Prendergast, Canice and Robert H. Topel. 1996. "Favoritism in Organizations." Journal of Political Economy, 104(5): 958-78.

Rotemberg, Julio J. 1994. "Human Relations in the Workplace." Journal of Political Economy, 102(4): 684-717.

Sacerdote, Bruce. 2001. "Peer Effects with Random Assignment: Results for Dartmouth Roommates." The Quarterly Journal of Economics, 116(2): 681-704.

Soetevent, Adriaan R. 2006. "Empirics of the Identification of Social Interactions; an Evaluation of the Approaches and Their Results." Journal of Economic Surveys, 20(2): 193-228.

Swidler, Steve and Elizabeth Goldreyer. 1998. "The Value of a Finance Journal Publication." The Journal of Finance, 53: 351-363.

Waldinger, Fabian. 2010. "Quality Matters: The Expulsion of Professors and the Consequences for PhD Student Outcomes in Nazi Germany." Journal of Political Economy, 118(4): 787-831.

Waldinger, Fabian. 2012. "Peer Effects in Science: Evidence from the Dismissal of Scientists in Nazi Germany." Review of Economic Studies, 79(2): 838-861. 


\section{Tables and Figures}

Figure 1: Cumulative distributions for citations to articles over the period 2000-2006, by journal

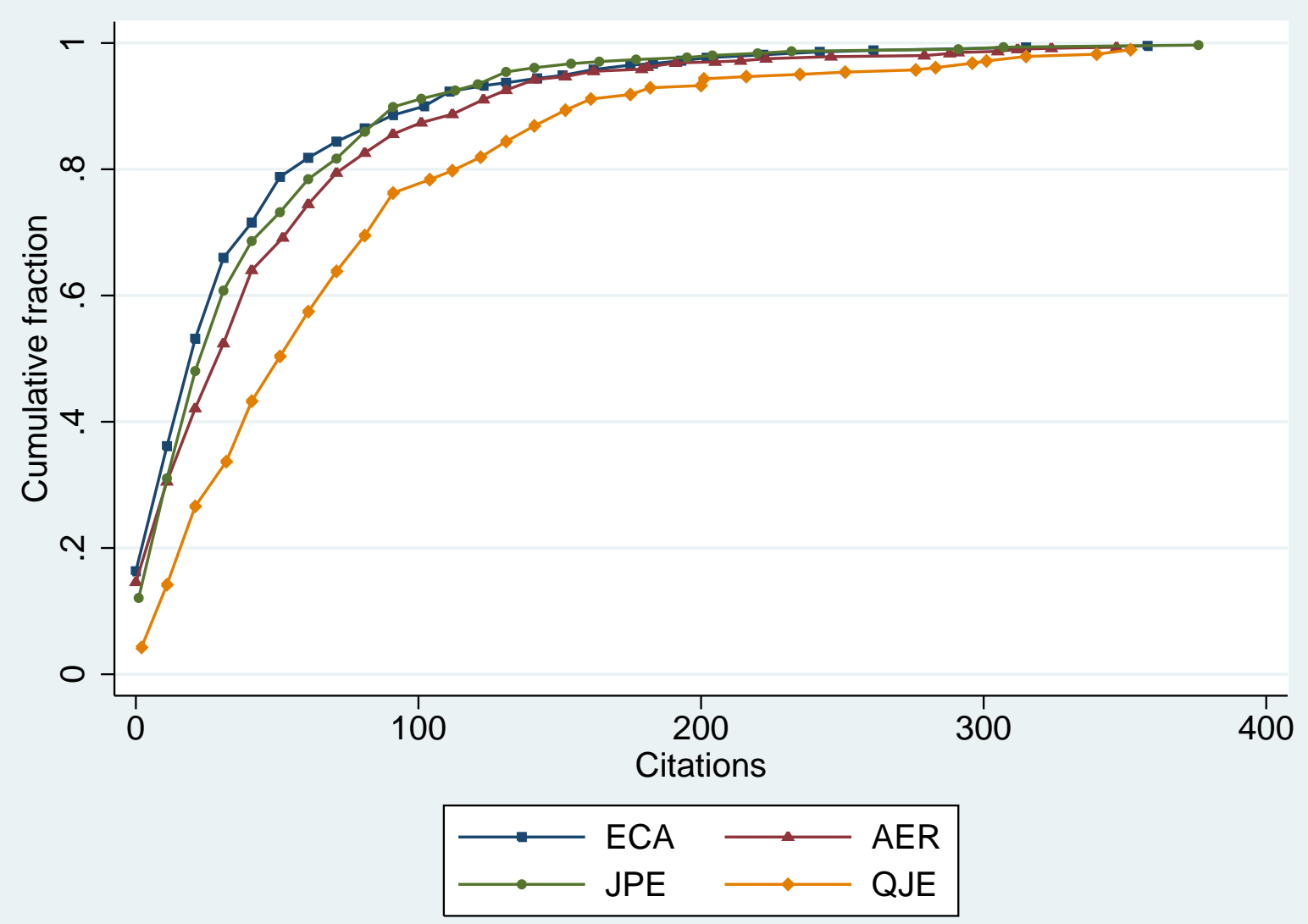

Notes: Data on citations were retrieved from Web of Science in January 2015. They refer to an article's number of citations in the first eight years after publication, including citations in working papers and self-citations. 
Figure 2: Authors' institution of appointment, by journal

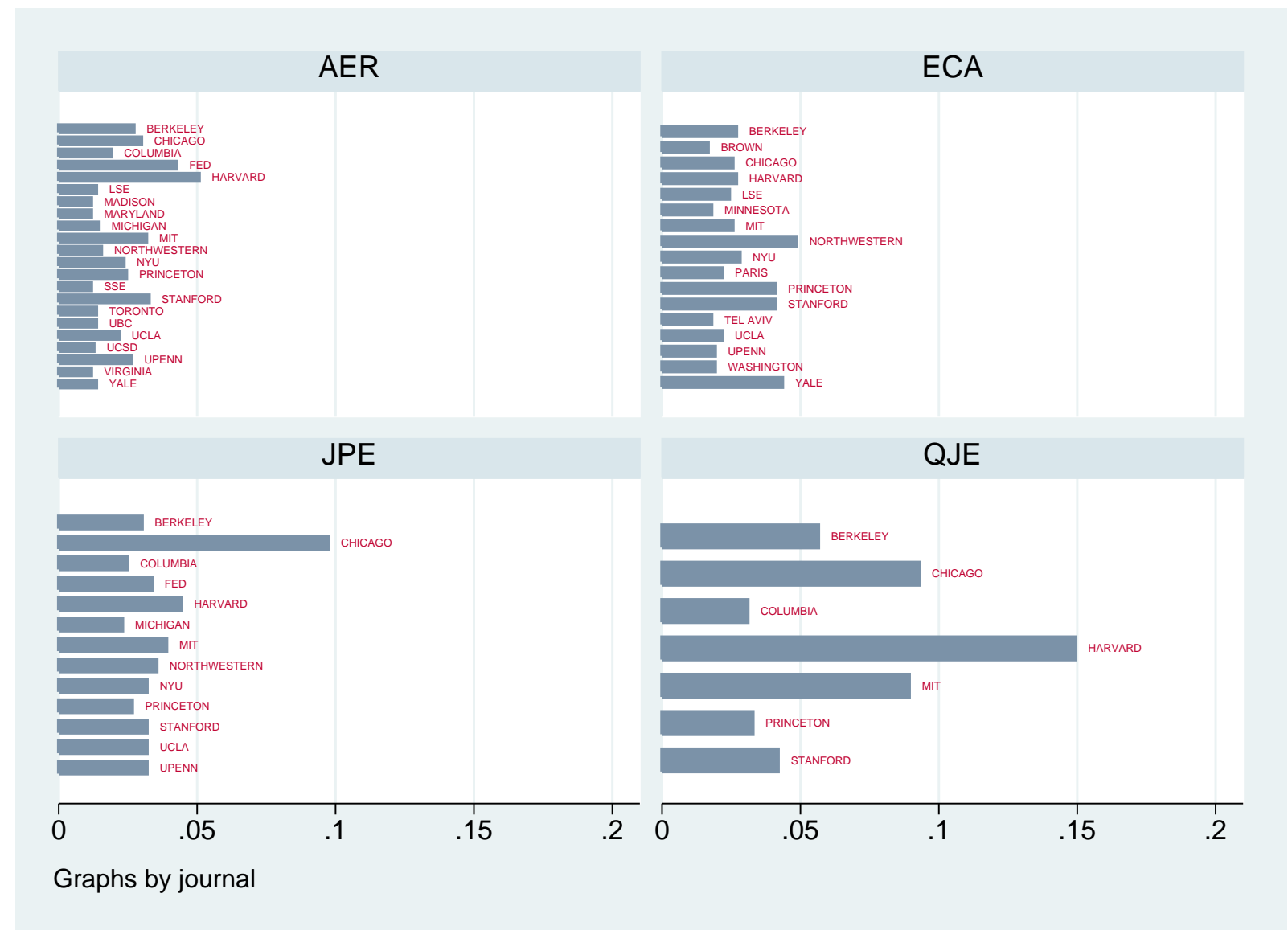

Notes: The figure plots the academic institutions that account for the first $50 \%$ of published articles over the period 2000-2006. These are institutions of appointment at the time of publication. 
Figure 3: Authors' institution of $\mathrm{PhD}$ award

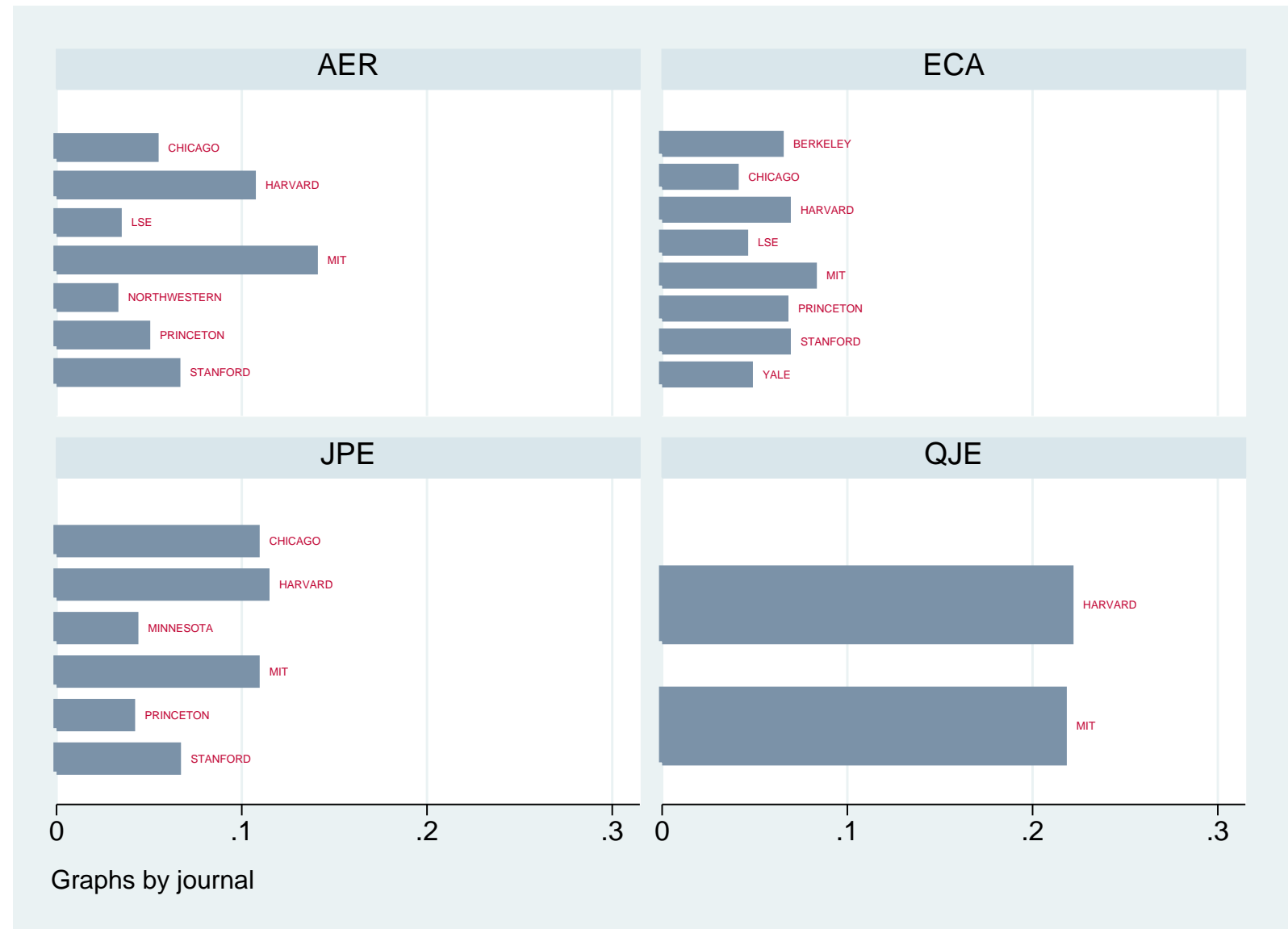

Notes: The figure plots the PhD institutions of authors that account for the first $50 \%$ of published articles over the period 2000-2006. 
Table 1: Articles' characteristics

\begin{tabular}{lccccc}
\hline \hline & All journals & AER & ECA & JPE & QJE \\
\hline Number of articles & 1620 & 603 & 429 & 306 & 282 \\
Number of pages & 25.92 & 17.90 & 27.23 & 29.87 & 36.78 \\
& {$[12.88]$} & {$[10.24]$} & {$[13.02]$} & {$[9.62]$} & {$[9.83]$} \\
Citations per article & 57.71 & 56.69 & 47.64 & 50.38 & 83.17 \\
& {$[71.50]$} & {$[68.64]$} & {$[62.50]$} & {$[66.20]$} & {$[88.27]$} \\
Number of authors & 1.94 & 1.94 & 1.92 & 1.94 & 2.03 \\
& {$[0.77]$} & {$[0.77]$} & {$[0.76]$} & {$[0.75]$} & {$[0.84]$} \\
JEL codes' share: & & & & & \\
C & 16.57 & 0.68 & 53.61 & 3.92 & 7.12 \\
D & 16.82 & 14.26 & 21.91 & 19.28 & 11.74 \\
E & 11.09 & 15.96 & 4.20 & 11.44 & 11.03 \\
F & 6.04 & 10.53 & 0.47 & 5.88 & 5.34 \\
G & 8.16 & 7.81 & 6.53 & 9.80 & 9.61 \\
H & 8.97 & 10.87 & 2.56 & 10.46 & 13.17 \\
I & 5.79 & 6.111 & 0.93 & 7.84 & 10.32 \\
J & 11.15 & 12.56 & 5.36 & 15.03 & 12.81 \\
& & & & & \\
Single author papers: & & & & & \\
Fraction & 29.32 & 29.35 & 30.77 & 29.74 & 26.60 \\
Citations per article & 47.18 & 49.50 & 43.72 & 39.48 & 57.13 \\
& {$[58.15]$} & {$[55.07]$} & {$[72.24]$} & {$[37.89]$} & {$[57.03]$} \\
Connected Papers: & & & & & \\
Same PhD & 10.25 & 9.45 & 8.16 & 9.80 & 15.60 \\
PhD Advisor & 14.75 & 11.61 & 15.15 & 14.71 & 20.92 \\
Same Faculty & 29.01 & 25.04 & 32.87 & 33.01 & 27.31 \\
Co-authors & 7.65 & 5.31 & 8.40 & 7.52 & 11.70 \\
Pooled & 42.78 & 37.15 & 45.22 & 44.44 & 49.29 \\
& & & & & \\
HHI index & 0.028 & 0.015 & 0.018 & 0.026 & 0.051 \\
\hline \hline
\end{tabular}

Notes: The table reports articles' characteristics by journal for the period 2000-2006. Appendix A provides information on the JEL classification system. Papers are defined as connected if at least one author was linked to the editor; connections are defined in Section 3.1. The Herfindahl index for journal $j$ is defined as $H H I_{j}=\sum_{i} s_{i j}^{2}$, where $s_{i j}$ is the fraction of all articles in journal $j$ written by authors affiliated with institution $i$. 
Table 2: Authors' and editors' characteristics

\begin{tabular}{lrr}
\hline \hline & Authors & Editors \\
\hline Number & 2,015 & 42 \\
Share of males & 90.34 & 92.36 \\
Share of early careers & 24.36 & 0 \\
Share of full professors & 51.42 & 96.53
\end{tabular}

Top institutions of appointment:

\begin{tabular}{lrr}
\hline Harvard & 6.13 & 15.28 \\
Chicago & 5.30 & 25.69 \\
MIT & 4.20 & 4.86 \\
Stanford & 3.63 & 4.17
\end{tabular}

Top PhD institutions:

\begin{tabular}{lrr}
\hline MIT & 13.26 & 31.25 \\
Harvard & 11.83 & 12.50 \\
Chicago & 6.33 & 8.33 \\
Stanford & 6.23 & 4.17 \\
Princeton & 5.40 & 4.86 \\
Berkeley & 4.03 & 2.78
\end{tabular}

\section{Share of connected authors:}

\begin{tabular}{lll}
\hline Same PhD & 24.41 & . \\
PhD Advisor & 39.47 & . \\
Same Faculty & 52.49 & \\
Co-authors & 12.36 \\
Pooled & 72.94 & . \\
\hline \hline
\end{tabular}

Notes: The table reports scholars characteristics for the period 2000-2006. Authors' and editors' characteristics refer to the ones at the time of publication and editorship respectively. Authors are connected if they are linked to at least one editor at any time; connections are defined in Section 3.1 . 


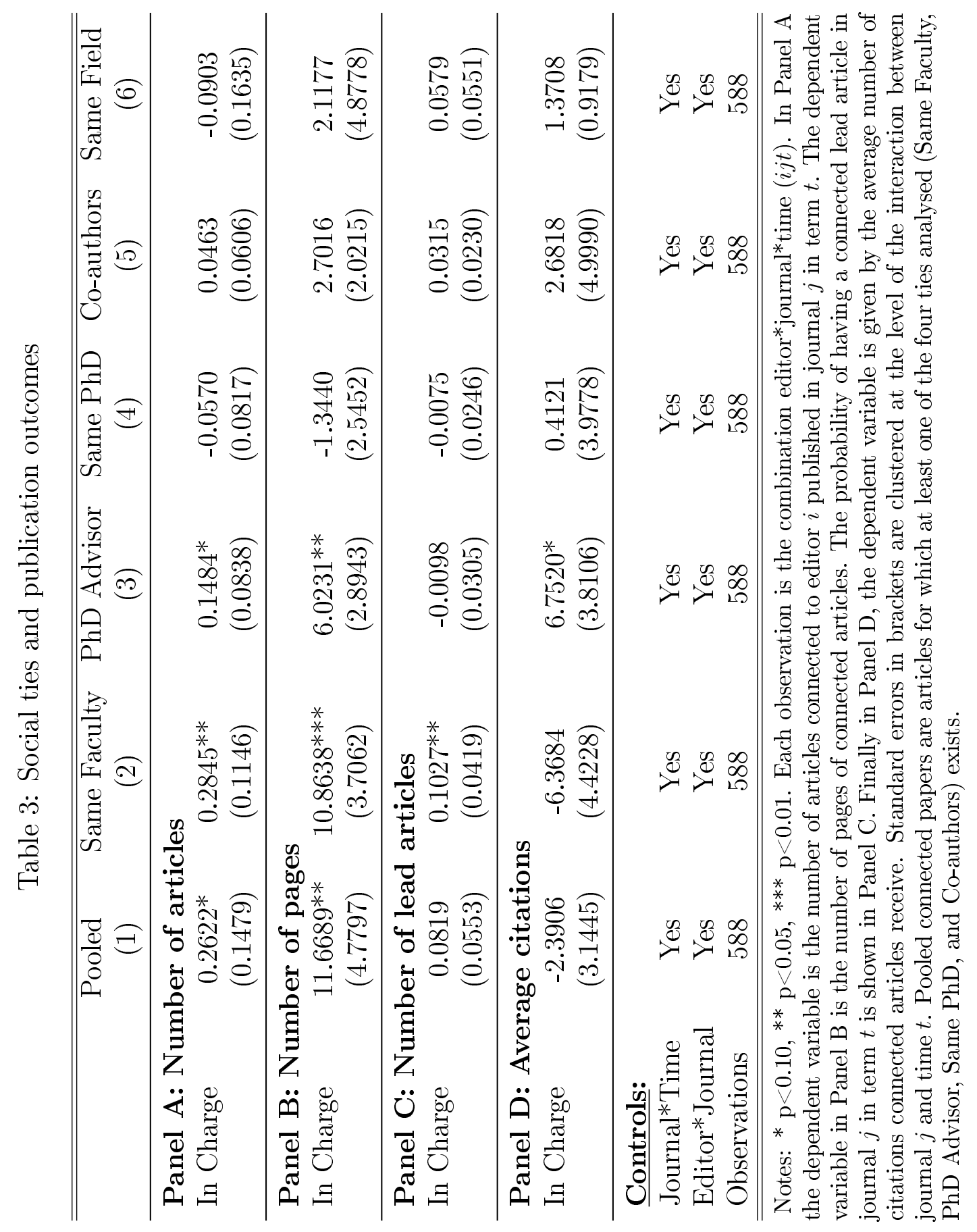




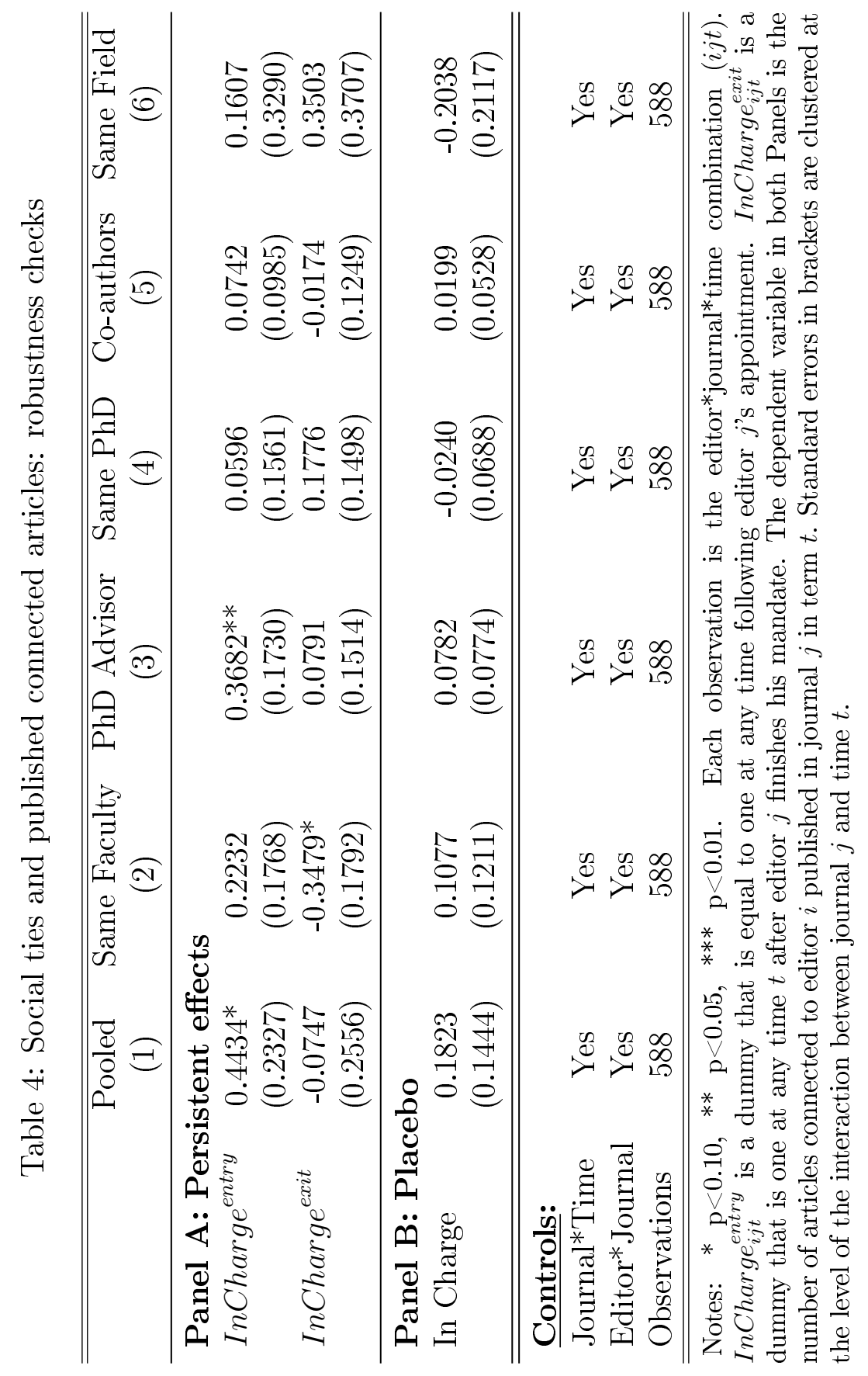




\section{Appendix A: JEL Classification}

Articles in this dataset are classified according to the JEL classification codes, a system that has been implemented by the Journal of Economic Literature $(J E L)$. There are 19 JEL categories, these are:

JEL: A - General Economics and Teaching

JEL: B - History of Economic Thought, Methodology, and Heterodox Approaches

JEL: C - Mathematical and Quantitative Methods

JEL: D - Microeconomics

JEL: E - Macroeconomics and Monetary Economics

JEL: F - International Economics

JEL: G - Financial Economics

JEL: H - Public Economics

JEL: I - Health, Education, and Welfare

JEL: J - Labor and Demographic Economics

JEL: K - Law and Economics

JEL: L - Industrial Organization

JEL: M - Business Administration and Business Economics; Marketing; Accounting

JEL: N - Economic History

JEL: O - Economic Development, Technological Change, and Growth

JEL: P - Economic Systems

JEL: Q - Agricultural and Natural Resource Economics; Environmental and Ecological Economics

JEL: R - Urban, Rural, and Regional Economics

JEL: Y - Miscellaneous Categories

JEL: Z - Other Special Topics 